Chapter 10

\title{
Signs and Symptoms
}

\author{
Valerio Barghini, Debora Donnini, \\ Alessandro Uzzau and Giorgio Soardo \\ Additional information is available at the end of the chapter
}

http://dx.doi.org/10.5772/56162

\section{Introduction}

Hepatocellular carcinoma (HCC) is often diagnosed after the tumor manifests clinical signs and symptoms. Early diagnosis is usually performed thanks to HCC screening programs for patients affected by liver cirrhosis or chronic viral hepatopathies using ultrasound and serum alfa-fetoprotien. In most HCC cases, clinical signs and symptoms of this tumor may occur several months after development, when therapy can not be curative, given the advanced tumor stage and underlying liver disease, which preclude curative options, such as ablation, resection, or liver transplantation.

Clinical features of HCC are often similar to those caused by the underlying hepatic disease. It is very hard for physicians to distinguish signs and symptoms of HCC in contests characterized by an advanced liver disease. Advanced liver cancer can be responsible for accelerated liver functions deterioration caused by the intrahepatic tumor growth.

In this chapter, we review the clinical signs and symptoms induced by advanced carcinoma. We also discuss particular clinical scenarios caused by metastases and paraneoplastic syndromes, sometimes described case reports in literature.

\section{Non-specific signs and symptoms}

Non-specific systemic signs and symptoms as asthenia, anorexia, weight loss, and nausea, are often present in patients with HCC (table 1). HCC should be suspected with the onset of these clinical features in patients at risk for this tumor. 


\subsection{Clinical aspects of cirrhosis}

Clinical signs and symptoms of hepatic cirrhosis that is often present in patients with HCC, usually mask the presence of an underlying early hepatocellular carcinoma [1]. Symptoms and signs of cirrhosis are often the only expression of the disease. Because of this, patients affected by HCC usually present at an advanced stage of the disease with clinical signs as jaundice, ascites, peripheral oedemas, neurologic manifestations of hepatic encephalopathy, bleeding, or infections. Other signs of hepatic cirrhosis include gynecomastia, palmar erythema, spider angiomas, axillary or chest hair loss, hypogonadism (testicular atrophy, loss of libido).

A large HCC can worsen the underlying hepatic disease, therefore in case of clinical worsening of a cirrhotic patient, onset of a HCC should be suspected.

\subsection{Hepatomegaly}

Hepatomegaly can be an expression of the tumor mass,(table 1) [1,2]. In case of HCC, the palpable edge of the liver is more often irregular, hard, with nodular consistency.

Hepatomegaly is more often present in patients without advanced cirrhosis [2]. In case of large tumors, the mass can cause asymmetry of the abdomen [3]. The costal margin can be deformed and the profile of lower ribs can be asymmetric. The right hemi-diaphragm can be elevated. This alteration of diaphragm profile can be asymptomatic or can cause mild respiratory symptoms. With thorax percussion is possible to detect an area of dullness, while trough auscultation is possible not to hear the vescicular murmur in case of elevation of diaphragm. HCC can also cause a pleural effusion. All these clinical aspects are difficult to be differentiated from signs and symptoms of the underlying chronic liver disease: Right diaphragm elevation is possible in case of hepatopathy not associated to HCC and pleural effusion can be the expression of an ascending ascitic fluid or of the anasarca state caused by cirrhosis and hypoalbuminemia.

\subsection{Vascular bruit}

Trough auscultation of the abdomen, an arterial bruit can be heard in patients affected by HCC. This bruit is typically heard throughout the liver and it is described to have different characteristic from other vascular abdominal auscultatory findings. In fact, usually, arterial bruit caused by abdominal aortic aneurysm or by renal artery stenosis are soft and short. Arterial bruit caused by HCC is usually a hard bruit and it is more prolonged than those caused by other conditions. This clinical sign is thought to be caused by the presence of an arteriovenous fistula in the context of the tumor [4], suggesting the presence of a highly vascularized HCC [5].

\section{Abdominal pain, portal vein thrombosis, rupture of HCC}

A frequent manifestation of onset of HCC is abdominal pain. The pain is usually mild, located in right hypochondrium and it can radiate to the right shoulder. Prior reports suggested that 
in black South African patients, abdominal pain is frequent in $95 \%$ of cases while it is referred by $46 \%, 51 \%$ and $38 \%$ of Japanese, Chinese and Italian patients, respectively (table 1 ).

Abdominal pain is more frequent in non cirrhotic patients, and in case of portal thrombosis [1]. Portal vein thrombosis has been found in (14-44\%) of autopsies of patients with HCC [6,7]. Patients with both cirrhosis and hepatic carcinoma have the highest risk to develop portal vein thrombosis [6]. Portal vein thrombosis is reported to be diagnosed during investigation for acute abdominal pain in $18 \%$ of cases in cirrhotic patients [8].

Other clinical manifestations of portal vein thrombosis and/or portal hypertension are hematemesis from rupture of esophageal varices, nausea, vomiting, anorexia, weight loss, diarrhea. Splenomegaly has been reported to be present in $75-100 \%$ of patients with portal vein thrombosis [9]. Bleeding from esophageal varices or from portal hypertensive gastropathy is the most common presenting symptom of portal vein thrombosis in cirrhotic patients $[8,10]$. In $43 \%$ of cases of Portal vein thrombosis in cirrhotic patients, diagnosis is done during a routine echo-Doppler examination [8].

If a cirrhotic patient present an acute pain, then bleeding from rupture of tumor should be suspected. HCC rupture causes a severe and sudden pain, and the patient can present the clinical features of an acute abdomen, with rebound and tenderness during physician palpation and an abdominal involuntary defense contraction. A hypovolemic state and signs and symptoms of acute anemia can be present. Clinical features of chronic anemia can be present in case of slow blood loss from HCC.

HCC rupture has been reported to be a rare condition in Western countries, occurring only in $3 \%$ of Italian patients [11], while spontaneous hemoperitoneum is more frequent in SubSaharian Africa and in Southeast Asia, being present in 10\% of patients at presentation [12].

Usually,HCC tumors bleedings are spontaneous, but in rare cases, they can be caused by external causes. The protrusion of HCC beyond the liver surface seems to be an important risk factor for HCC rupture [13]: hemorrhages occur more easily and can also be caused by slight external forces. So HCC rupture can be caused by abdominal traumas [14], vigorous muscular exertion, or rarely after forceful physician's palpation [15].

HCC rupture is also a rare complication of therapeutic procedures on HCC. For example after transcatheter arterial chemoembolization (TACE), HCC rupture occurs in less than $1 \%$ of patients [16].

The drainage of hematic peritoneal liquid in patient with acute abdominal pain can suggest the presence of a ruptured HCC, not being specific for this condition.

\subsection{Gastrointestinal bleeding}

A particular manifestation of HCC can be a bleeding from esophageal varices. This presentation is not frequent, occurring as first clinical sign only in $1 \%-8 \%$ of cases of HCC $[17,18]$ (table1). Variceal bleeding is caused by higher pressure in portal district which in turn can be caused by tumor invasion of this venous system and portal hypertension [17]. This portal invasion can be detected radiologically in $44-57 \%[17,18]$ of cases of variceal bleeding as 
presenting clinical manifestation of HCC. If variceal bleeding can be related with portal venous system invasion suggesting an advanced neoplastic disease, it does not seem to exist a relationship between this kind of clinical presentation and the size of the underlying tumor. Bleeding from esophageal varices is obviously a more frequent clinical presentation of HCC in patients with more advanced liver cirrhosis [18] and high degree of portal hypertension. However, HCC can present with variceal bleeding also in patients without a known history of hepatopathy [17].

Variceal bleeding can present with melena or hematemesis. Bleeding can be massive, leading to hypovolemic state and it is one of the known triggers of cirrhotic encephalopathy so that tremors, confusion till to coma, can be present in these patients too. Also infections can be caused by gastrointestinal bleeding in cirrhotic patients (22\% of cases) [19], therefore, clinical signs and symptoms of an abdominal infections can be present.

Additionally, $50 \%$ of causes of gastrointestinal hemorrhages are represented by hypertensive gastropathy, peptic ulcer and direct tumoral invasion of digestive tract [20,21].

\subsection{Jaundice}

Jaundice is a frequent sign of presentation of HCC. Some studies indicated that it is present at the diagnosis of HCC in $28 \%$ of African patients, but less frequent in Chinese, Japanese or European countries (table1).

Different pathologic conditions linked to HCC can explain the onset of jaundice. Jaundice can be expression of hepatic failure, due to extensive tumor infiltration of a cirrhotic liver or by worsening of the underlying hepatitis that can occur in presence of HCC. [22].

In other cases, jaundice result from obstruction of bile ducts by HCC. Clinical manifestation are those of typical cholestatic syndrome. In these cases jaundice is usually accompanied by itchiness, caused by elevation of serum level of bile acids, hypocolic stool and dark urine. All these symptoms can be presents also in the underlying liver disease, not being specific for biliary tract invasion.

The neoplastic obstruction can occur due to intraluminal biliary obstruction, extraluminal neoplastic compression or clot formation secondary to hemobilia caused by tumor invasion of biliary tree [23]. The presence of an intraluminal free-floating tumor fragment in the extrahepatic biliary tree may show an intermittent jaundice that can be associated with colicky pain [24]. Also in case of hemobilia a colicky pain can be present [5].

\subsection{Fever}

Fever of Unknown Origin can be a way of presentation of HCC $[25,26]$. It can be intermittent, and usually is accompanied by leukocytosis. Imaging studies are often necessary to differentiate an HCC from a liver abscess. Fever occur more frequently in patients with massive HCC and in non cirrhotic individuals [1]. 


\subsection{Caval invasion}

If HCC invades the inferior vena cava, signs and symptoms of venous insufficiency can appear. In this case relevant pitting edema can appear, usually bilaterally, affecting both inferior limbs, from the inguinal region. The invasion of the venous district, can worsen ascites and hepatomegaly [24].

Caval tumor thrombus can extend to the right atrium, causing dyspnea and heart failure [27]. When a patient presents signs and symptoms of right heart failure, such as jugular turgor, dyspnea, new onset of inferior limbs edema and worsening of hepatic insufficiency, heart tumoral invasion should always be suspected [28]. Anyway atrial invasion is reported to be also asymptomatic [29]. Pulmonary embolization by venous invasion is a rare, but reported primary manifestation of HCC [30].

\section{Age differences in presentation}

Patient's age can influence the clinical presentation of HCC. Signs and symptoms at presentation of HCC described in patients affected by hepatitis B are significantly different in patients younger and older than 40 years. Younger patients present more often with pain, hepatomegaly and ruptured HCC. Older patient present more often with ankle oedema and ascites. This is explained by the fact that in patients affected by viral hepatitis, advanced cirrhosis is more frequent in the older ones [2]. In younger patients it is more difficult that cirrhosis masks clinical aspect caused by HCC.

\begin{tabular}{ccccc}
\hline \multicolumn{5}{c}{ Clinical signs and symptoms in different geographic regions (\%) } \\
\hline Asymtomatic & Black African & Japan & China & Europe (Italy) \\
\hline Abdominal pain & - & - & 29,9 & 38 \\
\hline Ascites & 95 & 46 & 51 & 38 \\
\hline Palpable mass & 51 & 27 & 18 & 12 \\
\hline Hepatomegaly & 92 & 23 & 5 & 90 \\
\hline Ankle Edema & - & - & 54 & 14 \\
\hline Jaundice & - & 17 & 9 & 12 \\
\hline Fever & 28 & 17 & 2 & 3 \\
\hline Diarrhea & 35 & - & 17 & 3 \\
\hline Hemoperitoneum & - & 7 & - & 4 \\
\hline Variceal Bleeding & 2 & & 3 & 3 \\
\hline
\end{tabular}

Table 1. $[1,2,11,24]$ 


\section{Extrahepatic metastases}

Metastases from HCC, spread through lymphatic or hematic system, are more frequently placed in abdominal and thoracic lymph nodes, lung, bones, adrenal glands. Less frequent sites of metastases are brain, spleen and breast [31]. Rarely metastases can also be detected in digestive tube, pancreas, seminal vesicle and bladder [32].

When HCC is diagnosed, extrahepatic metastases, are present in more or less $40 \%$ of cases, $[32,33]$ and several signs and symptoms can be caused by this condition. Sometimes signs and symptoms caused by metastases are the only clinical manifestation of HCC [34]. Regional lymph nodes are affected in up to $60 \%$ of metastatic HCC, while distant lymphatic stations are involved only in $12 \%$ of these cases [32]. The frequencies of metastases in different sites are reported in (Table 2).

Pain and pathologic fractures can be caused by osteolytic metastases. Severe pain is present in $90 \%$ of patients with bone metastases [35]. Bone metastases are present in up $66 \%$ of patients in some studies, mostly in the transverse skeleton as in thoracic spine, lumbosacral spine, sacrum. Frequently they can also be present in ribs, skull, head of femur and peripheral bones $[24,32]$. Rarely HCC can have as only presentation pain or other symptoms caused by bone metastases, and this can also occur in non-common bone sites [36,37].

HCC metastases can cause also symptoms linked to nervous system. In fact in case of vertebral fractures, spinal cord compression can occur, causing neurological symptoms, leading to paraplegia in some cases. Clinical features of spinal compression can occur as complication of advanced known HCC, or rarely they can be the clinical presentation of this tumor [38].

Excluding lymph nodes, lung is the most common site of metastases ( $54 \%$ of metastatic HCC) [39].Lung metastases sometimes are causes of dyspnea, cough, hemoptysis, chest pain [40]. Fatal respiratory failure is described in more or less $20 \%$ of HCC lung metastatic tumors [39].

Brain metastases are not frequent, but often they cause important neurological symptoms, up to causing paralysis in most of these cases [39].

Peritoneal metastases can cause ascites and abdominal pain and they are present in more or less $10 \%$ of metastatic HCC [32]. Rarely, metastases were reported in appendix, and signs and symptoms typical of acute appendicitis, as pain in the right lower quadrant associated with tenderness at the physical examination, can be a clinical presentation of HCC [41].

\section{Paraneoplastic syndromes}

Paraneoplastic syndromes occur in $19-44 \%$ of patients affected by HCC [42,43]. The presence of paraneoplastic syndromes is described to be related with younger patients, with larger size tumor $(>10 \mathrm{~cm})$ and with presence of portal vein thrombosis [43].

Among patients that have paraneoplastic syndromes during the clinical course of HCC, most of them have a single paraneoplastic manifestation. Hypercholesterolemia, erythrocytosis, 
Frequency of metastases in different sites (\%)

\begin{tabular}{llll}
\hline & & & Not Frequent Sites \\
\hline Lungs & 55 & Brain & 2 \\
\hline Lymph Nodes & 53 & Rectum & 1 \\
\hline Regional & 41 & Spleen & 1 \\
\hline Distant & 12 & Diaphragm & 1 \\
\hline Musculoskeletal & 28 & Duodenum & 1 \\
\hline Adrenal & 11 & Esophagus & 1 \\
\hline Peritoneum and/or omenutm & 11 & Pancreas & 1 \\
\hline & & Seminal Vescicle & 1 \\
\hline
\end{tabular}

Table 2. [32]

hypoglycemia and hypercalcemia are some of the most common paraneoplastic manifestations of HCC. Only $7 \%$ of patients have 2 of these syndromes, and rarely can be present all of them $(<1 \%$ of cases) [42].

Below, there are described the most common paraneoplastic syndromes and there are also reported other manifestations described in some case reports. See (Table 3) for some of the reported paraneoplastc syndromes.

\subsection{Hypoglycemia}

Hypoglycemia is not an infrequent paraneoplastic syndrome caused by HCC, occurring in about $4,6-27 \%$ of the patients with advanced HCC [43-45]. Hypoglycemia is caused by the increased demand for glucose by the tumor together with a reduction of gluconeogenesis and glycogenolysis, due to a decreased residual liver tissue coupled with cachectic state and malnutrition that are often present in these patients [46]. Episodes of hypoglycemia caused by an advanced HCC typically occur in the last weeks before the death of the patients.

Another pathologic mechanism involved in causing hypoglycemia is overproduction by the tumor of Insulin-Like Growth Factor II [47]. Hypoglycemia caused by over production of IGF II occurs not only in late stage HCC, but also in the early phases of the neoplastic disease [44].

Hypoglycemia has been also described as the first clinical manifestation of HCC in some reports $[44,48]$.

\subsection{Hypercalcemia}

Hypercalcemia is described to occur in $7-12 \%$ of patients with HCC $[43,45,49]$. A PTH-like humoral factor is probably responsible of this paraneoplastic syndrome [50]. Hypercalcemia can also be caused by the presence of osteolytic bone metastases [51]. 
Hypercaclemic coma can occur in patients with HCC and it can be confused with hepatic encephalopathy [52].

\subsection{Hypercholesterolemia}

Paraneoplastic hypercholesterolemia is present in $11-20 \%$ of patients with HCC $[43,45,53]$. Hypercholesterolemia in patients with HCC has been related with a reduced expression of LDL receptor, as in familiar hypercholesterolemia. Clinical manifestation of hypercholesterolemia in patients with HCC are not reported, but increased cardiovascular risk can be present and manifestations typical of familiar hypercholesterolemia, as xanthelasmas could be possible.

\subsection{Erythrocytosis}

Erythrocytosis is present in 2-16\% of patients with HCC [45,54-58]. Higher levels of erythropoietin, produced by the tumor, have been reported [58]. Local hypoxia has been suggested to be the cause of overproduction of erythropoietin by large HCC tumors [58,59].

Erythrocytosis accompanied by high levels of erythropoietin has been described as a rare primary presentation of HCC [60].

\subsection{Thrombocytosis}

Thrombocytosis has been reported to be present in 3\% of cases of HCC. This paraneoplastic syndrome seems to occur in younger patients $(<60 \mathrm{yr})$, being related with the presence of a larger tumor and main portal vein tumor thrombosis representing an unfavorable prognostic factor [61]. Thrombocytosis has been described to be related with thrombopoietin production by the HCC [62]. A case of HCC associated with both thrombocytosis and acquired Von Willebrand disease has been reported [63].

\subsection{Arterial hypertension}

Arterial hypertension has been described as a paraneoplastic manifestation of HCC. Some cases of severe arterial blood pressure associated with high plasma level of angiotensin-I, accompanied with hypokalemia have been reported [64]. Elevated concentrations of angiotensinogen have been found, whether or not associated with higher plasma levels of renin. Overproduction of angiotensinogen and renin could both play a role in causing paraneoplastic hypertension in patients affected by HCC [65].

\subsection{Diarrhea}

Watery diarrhea is another manifestation that can occur in patients with HCC. Overproduction of intestinal peptides as gastrin and vasoactive intestinal peptide (VIP) is one possible explanation of the onset of diarrhea in these patients [66]. Diarrhea was also described to be a possible clinical presentation of HCC [67-69]. 


\subsection{Feminization}

Feminization is described to be present in patient with HCC, also in those not affected by liver cirrhosis, showing clinical signs and symptoms as gynecomastia, loss of body hair, loss of libido. Onset of spider naevi can be a sign of an underlying HCC and this finding has been reported more frequently in men than in women [70]. Studies about circulating sex hormones in patients affected by HCC have shown unclear results and a direct role of HCC in causing feminization is still not defined [71-74].

\section{Cutaneous manifestaion}

Various cutaneous manifestations have been reported as paraneoplastic syndromes caused by HCC. In rare cases, dermatomyositis has been described in patients affected by HCC, either associated or not to viral hepatitis. [75-77]. Also polymyositis can be a paraneoplastic manifestation of HCC. Polymyositis has been described also as a rare presenting manifestation of HCC, sometimes causing severe rhabdomyolysis [78-81].

A relationship between HCC and acquired porphyria cutanea tarda has been reportedin literature, [82-84].

Pityriasis rotunda is a rare cutaneous disease characterized by round/oval, hypo/hyperpigmented rash with scaling. The number of skin lesion is variable and the size is described to be between 1,5 to $25 \mathrm{~cm}$. The localization of the lesions is usually over the trunk, lower back and proximal extremities [85,86].

In South African Black patients with diagnosis of HCC, its prevalence is of $16 \%$, much higher than in patients affected by other diseases associated with pityriasis rotunda. In selected groups of people, the onset of this cutaneous disorder could represent a diagnostic instrument for HCC [87].

The sign of Leser-Trelat defined as the abrupt appearance and rapid increase in size and number of multiple seborrheic keratoses as a result of cancer development has been reported [88]. This sign has been reported also in association to HCC [89].

Also paraneoplastic pemphigus has been related to HCC [90].

\section{Neurological manifestations}

Neurologic paraneoplasic syndromes are rarely present in patients affected by HCC, such as multifocal necrotizing leukoencephalopathy leading to coma or non-inflammatory cerebral vasculopathy with widespread cortical and subcortical infarcts causing progressive hemiparesis and dysarthria, also in young patients [91,92].

Peripheral polyneuropathy with cranial nerve involvement has been described as a rare presenting manifestation of HCC [93]. 


\section{Other paraneoplastic syndromes}

Other paraneoplastic manifestations rarely described in patients with HCC are dysfibrinogennemia [94,95], cryofibrinogenemia [96], carcinoid syndrome [24], myasthenia gravis [97] and membranous glomerulonephritis [98].

\section{Paraneoplastic Syndromes}

\begin{tabular}{|c|c|c|c|}
\hline \multicolumn{4}{|c|}{ Usual Manifestations } \\
\hline Hypoglycemia & Hypercalcemia & Hypercholesterolemia & Erythrocytosis \\
\hline Thrombocytosis & Pityriasis Rotunda & & \\
\hline \multicolumn{4}{|c|}{ Reported Manifestations } \\
\hline Arterial Hypertension & $\begin{array}{c}\text { Dermatomyositis/ } \\
\text { Polymyositis }\end{array}$ & Porphyria cutanea tarda & Pemphigus \\
\hline Sign of Leser-Trelat & Diarrhea & Neurological manifestations & $\begin{array}{c}\text { Membranous } \\
\text { glomerulonephritis }\end{array}$ \\
\hline Dysfibrinogenemia & Cryofibrinogenemia & Carcinoid syndrome & Myasthenia grave \\
\hline
\end{tabular}

Table 3. Add caption

\section{Conclusion}

Clinical signs and symptoms of HCC are various. In absence of screening programs clinical signs can be helpful for diagnosis. Clinical signs are different depending on tumor size, vascular invasion, presence of cirrhosis and presence of metastases. Several paraneoplastic syndromes are described but our knowledge about some manifestation is limited to few published case reports.

\section{Author details}

Valerio Barghini, Debora Donnini, Alessandro Uzzau* and Giorgio Soardo*

*Address all correspondence to: soardo.giorgio@aoud.sanita.fvg.it

Department of Clinical and Experimental Sciences, University of Udine, Italy 


\section{References}

[1] Trevisani, F, Intino, D, Caraceni, P. E, Pizzo, P, Stefanini, M, \& Mazziotti, G. F. A, et al. Etiologic factors and clinical presentation of hepatocellular carcinoma. Differences between cirrhotic and non cirrhotic Italian patients. Cancer. (1995). May 1;, 75(9), 2220-32.

[2] Lam, C-M, Chan, a O. O, Ho, P, Ng, I. O-L, Lo, C. M, Liu, C. L, et al. Different presentation of hepatitis B-related hepatocellular carcinoma in a cohort of 1863 young and old patients- implications for screening. Alimentary pharmacology \& therapeutics. (2004). Apr $1 ;$, 19(7), 771-7.

[3] Sanders, C. F. The plain chest radiograph in seventy-five cases of primary carcinoma of the liver. Clinical radiology. (1968). Jul;, 19(3), 341-6.

[4] Sherman, H. I, \& Hardison, J. E. The Importance of a Coexistent Hepatic Rub and Bruit: A Clue to the Diagnosis of Cancer in the Liver. JAMA: The Journal of the American Medical Association. (1979). Apr 6;, 241(14), 1495-1495.

[5] Okuda, K O. H. Malignant Tumour. Oxford Textbook of Clinical Hepatology- Bircher, J Benhamou, J-P McIntyre, N Rizzetto, M Rodes, J.E. (1999). , 1505-1507.

[6] Ogren, M, Bergqvist, D, Björck, M, Acosta, S, Eriksson, H, \& Sternby, N. H. Portal vein thrombosis: prevalence, patient characteristics and lifetime risk: a population study based on 23,796 consecutive autopsies. World journal of gastroenterology. (2006). Apr 7; 12(13), 2115-9.

[7] Pirisi, M, Avellini, C, Fabris, C, Scott, C, Bardus, P, Soardo, G, et al. Portal vein thrombosis in hepatocellular carcinoma: age and sex distribution in an autopsy study. Journal of cancer research and clinical oncology. (1998). Jan;, 124(7), 397-400.

[8] Amitrano, L, Guardascione, M. A, Brancaccio, V, Margaglione, M, Manguso, F, Iannaccone, $\mathrm{L}$, et al. Risk factors and clinical presentation of portal vein thrombosis in patients with liver cirrhosis. Journal of hepatology. (2004). May;, 40(5), 736-41.

[9] Sobhonslidsuk, A, \& Reddy, K. R. Portal vein thrombosis: a concise review. The American journal of gastroenterology. (2002). Mar;" 97(3), 535-41.

[10] Belli, L, Romani, F, \& Sansalone, C. Portal thrombosis in cirrhotics. A retrospective analysis. Annals of surgery. (1986). Mar; , 203(3), 286-91.

[11] Vergara, V, Muratore, A, Bouzari, H, Polastri, R, Ferrero, A, Galatola, G, et al. Spontaneous rupture of hepatocelluar carcinoma: surgical resection and long-term survival. European journal of surgical oncology: the journal of the European Society of Surgical Oncology and the British Association of Surgical Oncology. (2000). Dec;" 26(8), 770-2. 
[12] Lai, E, Wu, K, Choi, T, Fan, S, \& Wong, J. Spontaneous ruptured hepatocellular carcinoma. An appraisal of surgical treatment. Annals of surgery. (1989). , 24-8.

[13] Hong, S, Kim, J, Wang, H, \& Kim, M. Risk Factors and Treatment Strategy of Ruptured Hepatocellular Carcinoma. The Korean Journal of Gastroenterology. (1998). Dec $1 ;$, 32(6), 749-56.

[14] Kew, M. C, \& Hodkinson, J. Rupture of hepatocellular carcinoma as a result of blunt abdominal trauma. The American journal of gastroenterology. (1991). Aug;, 86(8), 1083-5.

[15] Okuda, H, \& Okuda, K. Carcinome primitif du foie. (1993). , 1010-1053.

[16] Battula, N, Srinivasan, P, Madanur, M, Chava, S. P, Priest, O, Rela, M, et al. Ruptured hepatocellular carcinoma following chemoembolization: a western experience. Hepatobiliary \& pancreatic diseases international. (2007). Feb; 6(1), 49-51.

[17] Chen, C-H, Sjeu, J-C, Huang, G-T, Lee, H-S, Yang, P-M, Wong, J-M, et al. Characteristics of hepatocellular carcinoma presenting with variceal bleeding. Journal of Gastroenterology and Hepatology. (1998). Feb; 13(2), 170-4.

[18] Lang, B. H, Poon, R. T, Fan, S. T, \& Wong, J. Outcomes of patients with hepatocellular carcinoma presenting with variceal bleeding. The American journal of gastroenterology. (2004). Nov; 99(11), 2158-65.

[19] Bleichner, G, Boulanger, R, Squara, P, Sollet, J. P, \& Parent, A. Frequency of infections in cirrhotic patients presenting with acute gastrointestinal haemorrhage. The British journal of surgery. (1986). Sep; 73(9), 724-6.

[20] Yeo, W, Sung, J. Y, Ward, S. C, Chung, S. C, Lee, W. Y, Li, A. K, et al. A prospective study of upper gastrointestinal hemorrhage in patients with hepatocellular carcinoma. Digestive diseases and sciences. (1995). Dec;, 40(12), 2516-21.

[21] Humbert, P, Sarmiento, J, Boix, J, Planas, R, Quintero, E, Franquet, T, et al. Hepatocellular carcinoma presenting with bleeding due to duodenal perforation by the tumor. Endoscopy. (1987). Jan; 19(1), 37-8.

[22] Lau, W, Leung, K, Leung, T. W, Liew, C. T, Chan, M. S, Yu, S. C, et al. A logical approach to hepatocellular carcinoma presenting with jaundice. Annals of surgery. (1997). Mar;, 225(3), 281-5.

[23] Lau, W. Y, Leow, C. K, Leung, K. L, Leung, T. W, Chan, M, \& Yu, S. C. Cholangiographic features in the diagnosis and management of obstructive icteric type hepatocellular carcinoma. HPB surgery: a world journal of hepatic, pancreatic and biliary surgery. (2000). Jan; 11(5), 299-306.

[24] Ribero, D, \& Morris-stiff, G V. J. Presentation and Diagnosis. Hepatocellular Carcinoma- Lau W. Y. (2007). , 143-158. 
[25] Okuda, K, Kondo, Y, Nakano, M, Kage, M, Arakawa, M, Kojiro, M, et al. Hepatocellular carcinoma presenting with pyrexia and leukocytosis: report of five cases. Hepatology (Baltimore, Md.). (1991). Apr;; 13(4), 695-700.

[26] Hayashi, T, Honda, H, Kaneko, K, Fukuya, T, Tateshi, Y, Ro, T, et al. Hepatocellular carcinoma with pyrexia: report of a case. Radiation medicine. (1995). , 13(3), 133-6.

[27] Saïsse, J, Hardwigsen, J, Castellani, P, \& Caus, T. Le Treut YP. Budd-Chiari syndrome secondary to intracardiac extension of hepatocellular carcinoma. Two cases treated by radical resection. Hepato-gastroenterology. (2001). , 48(39), 836-9.

[28] Agelopoulou, P, Kapatais, A, Varounis, C, Grassos, C, Kalkandi, E, Kouris, N, et al. Hepatocellular carcinoma with invasion into the right atrium. Report of two cases and review of the literature. Hepato-gastroenterology. (2007). , 54(79), 2106-8.

[29] Ulus, T, Birdane, A, Dündar, E, \& Tünerir, B. Asymptomatic course of a metastatic mass completely filling the right atrium in a patient with hepatocellular carcinoma. Türk Kardiyoloji Derneği arşivi: Türk Kardiyoloji Derneğinin yayın organıdır. (2012). Jan;, 40(1), 52-4.

[30] Papp, E, Keszthelyi, Z, Kalmar, N-K, Papp, L, Weninger, C, Tornoczky, T, et al. Pulmonary embolization as primary manifestation of hepatocellular carcinoma with intracardiac penetration: a case report. World journal of gastroenterology. (2005). Apr $21 ; 11(15), 2357-9$.

[31] Uchino, K, Tateishi, R, Shiina, S, Kanda, M, Masuzaki, R, Kondo, Y, et al. Hepatocellular carcinoma with extrahepatic metastasis: clinical features and prognostic factors. Cancer. (2011). Oct 1; 117(19), 4475-83.

[32] Katyal, S, Oliver, J, Peterson, M, \& Ferris, J. Extrahepatic Metastases of Hepatocellular Carcinoma. Radiology. (2000). , 216(3), 698-703.

[33] Si, M-S, Amersi, F, Golish, S. R, Ortiz, J. A, Zaky, J, Finklestein, D, et al. Prevalence of metastases in hepatocellular carcinoma: risk factors and impact on survival. The American surgeon. (2003). Oct; 69(10), 879-85.

[34] Liaw, C. C, Ng, K. T, Chen, T. J, \& Liaw, Y. F. Hepatocellular carcinoma presenting as bone metastasis. Cancer. (1989). Oct 15;, 64(8), 1753-7.

[35] Natsuizaka, M, Omura, T, Akaike, T, Kuwata, Y, Yamazaki, K, Sato, T, et al. Clinical features of hepatocellular carcinoma with extrahepatic metastases. Journal of gastroenterology and hepatology. (2005). Nov;, 20(11), 1781-7.

[36] Mantonakis, E. I, Margariti, T. S, Petrou, A. S, Stofas, A. C, Lazaris, A. C, Papalampros, A. E, et al. A pathological fracture and a solitary mass in the right clavicle: an unusual first presentation of HCC and the role of immunohistochemistry. World journal of surgical oncology. BioMed Central Ltd; (2012). Jan;10(1):50. 
[37] Shim, Y. S, Ahn, J. Y, Cho, J. H, \& Lee, K. S. Solitary skull metastasis as initial manifestation of hepatocellular carcinoma. World journal of surgical oncology. (2008). Jan; 6:66.

[38] Doval, D. C, Bhatia, K, Vaid, A. K, Pavithran, K, Sharma, J. B, Hazarika, D, et al. Spinal cord compression secondary to bone metastases from hepatocellular carcinoma. World journal of gastroenterology. (2006). Aug 28; 12(32), 5247-52.

[39] Natsuizaka, M, Omura, T, Akaike, T, Kuwata, Y, Yamazaki, K, Sato, T, et al. Clinical features of hepatocellular carcinoma with extrahepatic metastases. Journal of gastroenterology and hepatology. (2005). Nov; 20(11), 1781-7.

[40] Shuangshoti, S. Hepatocellular carcinoma having progressive dyspnea as clinical presentation. Journal of the Medical Association of Thailand = Chotmaihet thangphaet. (1996). Nov; 79(11), 744-8.

[41] Kim, H. C, Yang, D. M, Jin, W, Kim, G. Y, \& Choi, S. I. Metastasis to the appendix from a hepatocellular carcinoma manifesting as acute appendicitis: CT findings. The British journal of radiology. (2008). Jul;81(967):e, 194-6.

[42] Luo, J. C, Hwang, S. J, Wu, J. C, Li, C. P, Hsiao, L. T, Lai, C. R, et al. Paraneoplastic syndromes in patients with hepatocellular carcinoma in Taiwan. Cancer. (1999). Sep $1 ;$, 86(5), 799-804.

[43] Huh, U, Kim, J, Kim, B, \& Nam, K. The incidence and clinical significance of paraneoplastic syndromes in patients with hepatocellular carcinoma. Korean Journal of Hepatology. (2005). , 11(3), 275-83.

[44] Sorlini, M, Benini, F, Cravarezza, P, \& Romanelli, G. Hypoglycemia, an atypical early sign of hepatocellular carcinoma. Journal of gastrointestinal cancer. (2010). Sep; 41(3), 209-11.

[45] Teniola, S. O, \& Ogunleye, I. O. Paraneoplastic syndromes in primary liver cell carcinoma in Nigeria. Tropical and geographical medicine. (1994). Jan;, 46(1), $20-2$.

[46] Mcfadzean, A. J, \& Yeung, R. T. Further observations on hypoglycaemia in hepatocellular carcinoma. The American journal of medicine. (1969). Aug;, 47(2), 220-35.

[47] Wu, J. C, Daughaday, W. H, Lee, S. D, Hsiao, T. S, Chou, C. K, Lin, H. D, et al. Radioimmunoassay of serum IGF-I and IGF-II in patients with chronic liver diseases and hepatocellular carcinoma with or without hypoglycemia. The Journal of laboratory and clinical medicine. (1988). Nov; $112(5), 589-94$.

[48] Nikeghbalian, S, Bananzadeh, A, \& Yarmohammadi, H. Hypoglycemia, the first presenting sign of hepatocellular carcinoma. Saudi medical journal. (2006). Mar;, 27(3), 387-8. 
[49] Panesar, N. S, Au, K. M, Leung, N. W, Shek, C. C, \& Swaminathan, R. Nephrogenous cyclic AMP in primary hepatocellular carcinoma patients with or without hypercalcaemia. Clinical endocrinology. (1991). Dec;, 35(6), 527-32.

[50] Yen, T. C, Hwang, S. J, Wang, C. C, Lee, S. D, \& Yeh, S. H. Hypercalcemia and parathyroid hormone-related protein in hepatocellular carcinoma. Liver. (1993). Dec; 13(6), 311-5.

[51] Clines, G. A. Mechanisms and treatment of hypercalcemia of malignancy. Current opinion in endocrinology, diabetes, and obesity. (2011). Dec;, 18(6), 339-46.

[52] Tudela, P, Soldevila, B, Mòdol, J. M, \& Domènech, E. Hypercalcemic encephalopathy in a patient with hepatocellular carcinoma. Digestive diseases and sciences. (2007). Nov; 52(11), 3296-7.

[53] Hwang, S. J, Lee, S. D, Chang, C. F, Wu, J. C, Tsay, S. H, Lui, W. Y, et al. Hypercholesterolaemia in patients with hepatocellular carcinoma. Journal of gastroenterology and hepatology. (2008). , 7(5), 491-6.

[54] Hwang, S. J, Lee, S. D, Wu, J. C, Chang, C. F, Lu, C. L, Tsay, S. H, et al. Clinical evaluation of erythrocytosis in patients with hepatocellular carcinoma. Zhonghua yi xue za zhi = Chinese medical journal; Free China ed. (1994). May;, 53(5), 262-9.

[55] Sawabe, Y, Iida, S, Tabata, Y, \& Yonemitsu, H. Serum erythropoietin measurements by a one-step sandwich enzyme linked immunosorbent assay in patients with hepatocellular carcinoma and liver cirrhosis. Japanese journal of clinical oncology. (1993). Oct;, 23(5), 273-7.

[56] Mcfadzean, A. J, Todd, D, \& Tsang, K. C. Polycythemia in primary carcinoma of the liver. Blood. (1958). May;, 13(5), 427-35.

[57] Jacobson, R. J, Lowenthal, M. N, \& Kew, M. C. Erythrocytosis in hepatocellular cancer. South African medical journal = Suid-Afrikaanse tydskrif vir geneeskunde. (1978). Apr 29;, 53(17), 658-60.

[58] Matsuyama, M, \& Yamazaki, O. Erythrocytosis caused by an erythropoietin- producing hepatocellular carcinoma. Journal of surgical oncology. (2000). May):, 197-202.

[59] Tso, S. C, \& Hua, A. S. Erythrocytosis in hepatocellular carcinoma: a compensatory phenomenon. British journal of haematology. (1974). Dec;, 28(4), 497-503.

[60] Chang, P-E, \& Tan, C-K. Paraneoplastic erythrocytosis as a primary presentation of hepatocellular carcinoma. Indian journal of medical sciences [Internet]. Medknow Publications; (2009). May 1;63(5):202-3. Available from: http://www.indianjmedsci.org/article.asp?issn=0019-5359; year=2009; spage=202;epage=203; aulast=Chang

[61] Hwang, S-J, Luo, J-C, Li, C-P, Chu, C-W, Wu, J-C, Lai, C-R, et al. Thrombocytosis: a paraneoplastic syndrome in patients with hepatocellular carcinoma. World journal of gastroenterology. (2004). Sep 1; 10(17), 2472-7. 
[62] Ryu, T, Nishimura, S, Miura, H, Yamada, H, Morita, H, Miyazaki, H, et al. Thrombopoietin-producing hepatocellular carcinoma. Internal medicine (Tokyo, Japan). (2003). Aug;, 42(8), 730-4.

[63] Chen, C-C, Chang, J-Y, Liu, K-J, Chan, C, Ho, C-H, Lee, S-C, et al. Hepatocellular carcinoma associated with acquired von Willebrand disease and extreme thrombocytosis. Annals of oncology. (2005). Jun; 16(6), 988-9.

[64] Arai, H, Saitoh, S, Matsumoto, T, Makita, F, Mitsugi, S, Yuasa, K, et al. Hypertension as a paraneoplastic syndrome in hepatocellular carcinoma. Journal of gastroenterology. (1999). Aug;, 34(4), 530-4.

[65] Kew, M. C, Leckie, B. J, \& Greeff, M. C. Arterial hypertension as a paraneoplastic phenomenon in hepatocellular carcinoma. Archives of internal medicine. (1989). Sep; 149(9), 2111-3.

[66] Bialecki, E. S. Di Bisceglie AM. Diagnosis of hepatocellular carcinoma. HPB: the official journal of the International Hepato Pancreato Biliary Association. (2005). Jan; $7(1), 26-34$.

[67] Steiner, E, Velt, P, Gutierrez, O, Schwartz, S, \& Chey, W. Hepatocellular carcinoma presenting with intractable diarrhea. A radiologic-pathologic correlation. Archives of surgery (Chicago, Ill.: 1960). (1986). Jul;, 121(7), 849-51.

[68] Bruix, J, Castells, A, Calvet, X, Feu, F, Bru, C, Solé, M, et al. Diarrhea as a presenting symptom of hepatocellular carcinoma. Digestive diseases and sciences. (1990). Jun; 35(6), 681-5.

[69] Giannelli, G, Pierri, F, Schiraldi, O, \& Antonaci, S. Diarrhea as first clinical manifestation of hepatocellular carcinoma. Recenti progressi in medicina. (2002). Sep; 93(9), 478-81.

[70] Lai, C, Gregory, P, Wu, P, \& Lok, A. Hepatocellular carcinoma in Chinese males and females. Possible causes for the male predominance. Cancer. (1987). , 60(5), 1107-10.

[71] Pignata, S, Daniele, B, Galati, M. G, Esposito, G, Vallone, P, Fiore, F, et al. Oestradiol and testosterone blood levels in patients with viral cirrhosis and hepatocellular carcinoma. European journal of gastroenterology \& hepatology. (1997). Mar;, 9(3), 283-6.

[72] Olubuyide, I. O, \& Ola, O. S. Clinical feminisation and sex hormone concentrations in Nigerian men with cirrhosis with and without hepatocellular carcinoma. The British journal of clinical practice. (1994). , 48(2), 70-2.

[73] Salles, G. Vital Durand D, Mackiewicz R, Pugeat M, Levrat R. Hepatocellular carcinoma and hyperestrogenia in a male. Gastroentérologie clinique et biologique. (1987). 
[74] Lampropoulou-karatzas, C, Goritsas, P, \& Makri, M. G. Low serum testosterone: a special feature of hepatocellular carcinoma. The European journal of medicine. (1993). Jan;, 2(1), 23-7.

[75] Toshikuni, N, Torigoe, R, Mitsunaga, M, Omoto, A, \& Nakashima, K. Dermatomyositis associated with hepatocellular carcinoma in an elderly female patient with hepatitis C virus-related liver cirrhosis. World journal of gastroenterology. (2006). Mar 14; 12(10), 1641-4.

[76] Kee, S-J, Kim, T-J, Lee, S-J, Cho, Y-N, Park, S-C, Kim, J-S, et al. Dermatomyositis associated with hepatitis B virus-related hepatocellular carcinoma. Rheumatology international. (2009). Mar;, 29(5), 595-9.

[77] Apostolidis, L, Kahlert, C, Siegmund, A, Thom, R, Horstmann, S, Jäger, D, et al. Remission of paraneoplastic dermatomyositis associated with hepatocellular carcinoma under prednisolone and azathiopin, and concommittant sorafenib. Onkologie. (2009). Feb;32(1-2):50-3.

[78] Kim, M-J, Kim, J-A, Sung, M-S, \& Min, J-K. Hepatocellular carcinoma,polymyositis,rhabdomyolysis, and acute renal failure. Journal of Korean medical science. (2004). Dec;, 19(6), 891-4.

[79] Tekaya, R, Abdelghni, K, \& Abdelmoula, L. Ben Hadj Yahia C, Chaabouni L, Zouari R. Hepatocellular carcinoma with polymyositis as an initial symptom: a case report. Acta clinica Belgica. (2011). , 66(1), 53-4.

[80] Hasegawa, K, Uesugi, H, Kubota, K, Ugawa, Y, Murayama, S, Kobayashi, T, et al. Polymyositis as a paraneoplastic manifestation of hepatocellular carcinoma. Hepatogastroenterology. (2000). , 47(35), 1425-7.

[81] Kishore, D, Khurana, V, Raj, A, Gambhir, I. S, \& Diwaker, A. Hepatocellular carcinoma presenting as polymyositis: a paraneoplastic syndrome. Annals of Saudi medicine [Internet]. (2011). Available from: http://www.pubmedcentral.nih.gov/ articlerender.fcgi?artid=3183691\&tool=pmcentrez\&rendertype=abstract, 31(5), 533-5.

[82] Ishibashi, H, Matsunaga, T, \& Dohmen, K. Association of cirrhosis and hepatocellular carcinoma with porphyria cutanea tarda. Nihon rinsho. Japanese journal of clinical medicine. (1995). Jun;, 53(6), 1474-8.

[83] Huang, W. S, Liao, L. Y, Wang, C. S, \& Chen, P. H. Hepatocellular carcinoma presenting with acquired porphyria: a case report and review of the literature. Changgeng yi xue za zhi / Changgeng ji nian yi yuan = Chang Gung medical journal / Chang Gung Memorial Hospital. (1999). Mar;, 22(1), 111-6.

[84] Fracanzani, A. L, Taioli, E, Sampietro, M, Fatta, E, Bertelli, C, Fiorelli, G, et al. Liver cancer risk is increased in patients with porphyria cutanea tarda in comparison to matched control patients with chronic liver disease. Journal of hepatology. (2001). Oct $1 ;$; 35(4), 498-503. 
[85] Gupta, S. Pityriasis rotunda mimicking tinea cruris/corporis and erythrasma in an Indian patient. The Journal of dermatology. (2001). Jan;, 28(1), 50-3.

[86] DiBisceglie AMHodkinson HJ, Berkowitz I, Kew MC. Pityriasis rotunda. A cutaneous marker of hepatocellular carcinoma in South African blacks. Archives of dermatology. (1986). Jul;, 122(7), 802-4.

[87] Berkowitz, I, Hodkinson, H. J, \& Kew, M. C. DiBisceglie AM. Pityriasis rotunda as a cutaneous marker of hepatocellular carcinoma: a comparison with its prevalence in other diseases. The British journal of dermatology. (1989). Apr;, 120(4), 545-9.

[88] Schwartz, R. A. Sign of Leser-Trélat. Journal of the American Academy of Dermatology. (1996). Jul;, 35(1), 88-95.

[89] Tajima, H, Mitsuoka, S, Ohtsuka, E, Nakamura, Y, Nakayama, T, Satoh, Y, et al. A case of hepatocellular carcinoma with the sign of Leser-Trelat: a possible role of a cutaneous marker for internal malignancy. Japanese journal of medicine. (1991). , 30(1), $53-6$.

[90] Yokokura, H, Demitsu, T, Kakurai, M, Umemoto, N, Azuma, R, Yamada, T, et al. Paraneoplastic pemphigus mimicking erosive mucosal lichen planus associated with primary hepatocellular carcinoma. The Journal of dermatology. (2006). Dec;, 33(12), 842-5.

[91] Phanthumchinda, K, \& Rungruxsirivorn, S. Encephaloradiculopathy: a non-metastatic complication of hepatocellular carcinoma. Journal of the Medical Association of Thailand = Chotmaihet thangphaet. (1991). May;, 74(5), 288-91.

[92] Norris, S, Rajendiran, S, Sheahan, K, Murphy, S, Royston, D, Alyusuf, R, et al. Noncirrhotic hepatoma presenting with paraneoplastic neurologic manifestations: two cases. The American journal of gastroenterology. (1997). Oct;, 92(10), 1923-6.

[93] Hatzis, G. S, Delladetsima, I, \& Koufos, C. Hepatocellular carcinoma presenting with paraneoplastic neurologic syndrome in a hepatitis B surface antigen-positive patient. Journal of clinical gastroenterology. (1998). Mar;, 26(2), 144-7.

[94] Von Felten, A, Straub, P. W, \& Frick, P. G. Dysfibrinogenemia in a patient with primary hepatoma. First observation of an acquired abnormality of fibrin monomer aggregation. The New England journal of medicine. (1969). Feb 20;, 280(8), 405-9.

[95] Gralnick, H. R, Givelber, H, \& Abrams, E. Dysfibrinogenemia associated with hepatoma. Increased carbohydrate content of the fibrinogen molecule. The New England journal of medicine. (1978). Aug 3;, 299(5), 221-6.

[96] CryofibrinogenemiaMultiple Dysproteinemias, and Hypervolemia in a Patient with a Primary Hepatoma. Annals of Internal Medicine. (1966). Mar 1;, 64(3), 658-64.

[97] Vautravers, C, Rat, P, Cercueil, J-P, Moreau, T, Horiot, J-C, \& Chauffert, B. Hepatocellular carcinoma presenting as paraneoplastic myasthenia gravis. European journal 
of internal medicine. European Federation of Internal Medicine; (2008). Dec;19(8):e, 86-7.

[98] Texier, F, Dharancy, S, Provot, F, Augusto, D, Mortier, P-E, Mathurin, P, et al. Membranous glomerulonephritis complicating hepatocellular carcinoma. Gastroentérologie clinique et biologique. (2004). Pt 1):605-7. 
